Presented at the 3rd European Conference on Energy-Efficient Lighting "Right Light Three", Newcastle upon Tyne, England, June 18-21, 1995.

\title{
A Photometric and Energy Assessment of a Novel Lighting System
}

\author{
Doug Crawford, Carl Gould, Michael Packer, Francis Rubinstein, Michael Siminovitch \\ Environmental Energy Technologies Division \\ Building Technologies Department \\ Lawrence Berkeley National Laboratory \\ University of California \\ Berkeley, California 94720
}

June 1995

This work was supported by the Assistant Secretary for Energy Efficiency and Renewable Energy, Office of Building Technology, State and Community Programs, Office of Building Equipment of the U.S. Department of Energy under Contract No. DE-AC03-76SF00098. 


\section{DISCLAIMER}

This report was prepared as an account of work sponsored by an agency of the United States Government. Neither the United States Government nor any agency thereof, nor any of their employees, make any warranty, express or implied, or assumes any legal liability or responsibility for the accuracy, completeness, or usefulness of any information, apparatus, product, or process disclosed, or represents that its use would not infringe privately owned rights. Reference herein to any specific commercial product, process, or service by trade name, trademark, manufacturer, or otherwise does not necessarily constitute or imply its endorsement, recommendation, or favoring by the United States Government or any agency thereof. The views and opinions of authors expressed herein do not necessarily state or reflect those of the United States Government or any agency thereof. 


\section{DISCLAIMER}

Portions of this document may be illegible in electronic image products. Images are produced from the best available original document. 


\title{
A PHOTOMETRIC AND ENERGY ASSESSMENT OF A NOVEL LIGHTING SYSTEM
}

\author{
Doug Crawford \\ Carl Gould, Michael Packer, Francis Rubinstein, Michael Siminovitch \\ Lighting Research Group \\ Lawrence Berkeley Laboratory \\ University of California \\ Berkeley, California 94720
}

\begin{abstract}
This paper describes the results of a photometric and energy analysis that was conducted on a new light guide and sulfur lamp system recently installed at both the U.S. Department of Energy's Forrestal building and the Smithsonian Institution's National Air and Space Museum. This system couples high lumen output, high efficiency sulfur lamps to hollow light guides lined with a reflective prismatic film. At the Forrestal building the system lights a large roadway and plaza area that lies beneath a section of the building. It has been designed to completely replace the grid of $\mathbf{2 8 0}$ mercury vapor lamps formerly used to illuminate the space. At the National Air and Space Museum a similar system illuminates Gallery 114, which houses the large rocket displays from the U.S. Space program. This paper outlines the unique operational and design characteristics of this highly efficient distribution system and details the results of field studies that characterize the significant energy savings and increased illumination levels that have been achieved. The projected savings in maintenance costs, due to longer lamp life and a reduction of the total number of lamps, is also presented.
\end{abstract}

\section{INTRODUCTION}

Two sites in Washington D.C. were chosen to demonstrate a new lighting system. Microwave driven, electrodeless sulfur lamps, coupled with prismatic film lined hollow light guides were installed at the Smithsonian National Air and Space Museum (NASM) and the U.S. Department of Energy's Forrestal building in October, 1994. This paper describes a photometric and energy analysis of the performance of this new lighting system and a comparison with the previous lighting systems for these sites.

These locations are ideal for the installation of sulfur lamp/light guide systems in that they both have demanding maintenance requirements for their respective lighting systems (Gilmore 1988). At the Forrestal Building, an exterior plaza with a high ceiling above pedestrian walkways and a bisecting roadway, was selected for the new light system installation. Maintenance of the previous multiple lamp system at the Forrestal plaza is a labor intensive program due to its physical features. Gallery 114 at NASM was chosen due to the difficulty in maintaining multiple, high ceiling light fixtures in the vicinity of the large rocket displays. At the time of the sulfur lamp installations, the existing lighting systems at both the Forrestal Building and NASM were in need of extensive relamping and fixture replacement. Analysis of the performance of the new sulfur lamp/light guide system shows decreased energy consumption, increased illumination levels and greatly reduced maintenance requirements over the previous lighting systems.

\section{FORRESTAL SITE}

The outdoor plaza of the Forrestal Building served as the location for a single $73 \mathrm{~m}$ light guide optically coupled with two sulfurs lamps, one at each end (fig. 1). The plaza is a large open air pedestrian area parallel to the Capital Mall with a roadway cutting through its center. Above the central region of the plaza is a suspended ceiling which contains the original lighting system for the plaza. 
Figure 1. Forrestal plaza

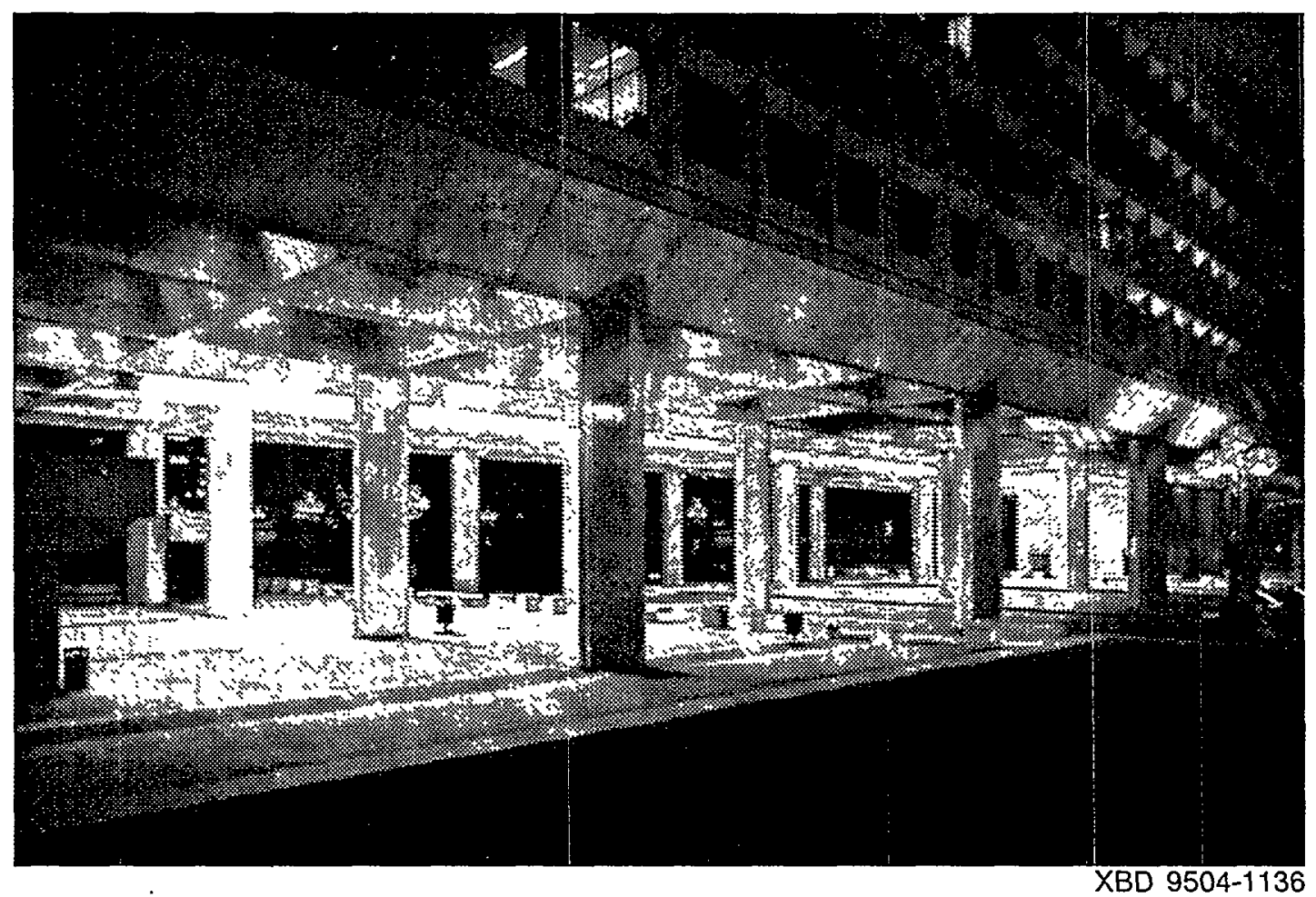

The concrete ceiling is approximately $10 \mathrm{~m}$ above the plaza floor and is characterized by a series of regularly spaced, recessed coffers; resembling a large, concrete waffle iron. The majority of the coffers are square with $4.1 \mathrm{~m}$ sides, have a depth of $1.7 \mathrm{~m}$ with sloping sides and are separated by $56 \mathrm{~cm}$ wide birms. Each of the square coffers houses four $175 \mathrm{~W}$ mercury high intensity discharge (HID) lamps.

Archive records from the Forrestal building indicate that the original lighting design utilized four 500 watt incandescent lamps per coffer. The site was later retrofitted with PAR type reflector lamps. The existing system was installed roughly ten years ago and consists of $280175 \mathrm{~W}$ mercury HID lamps. Physical observations and on-site measurements indicate that the new mercury lamps were placed inside the fixtures intended for the PAR type reflector lamps, resulting in a poor fixture efficiency configuration.

\section{Methods}

The two main criteria for evaluating the original (mercury HID) and new (sulfur lamp) lighting systems were the measured illumination levels and the energy consumption for each of the lighting systems. Ideally, a revamped version of the poorly maintained HID system, with new lamps and clean fixtures, would have provided a more useful comparison of the two systems. However, replacement of lamps and fixtures was cost prohibitive, therefore comparisons are based on the actual conditions in place.

Horizontal illuminance levels were measured with Tektronix $\mathrm{J17}$ illuminance meters on a regularly spaced grid beneath the central region of the plaza. The grid contained 343 measurement points on three meter centers over a $43 \mathrm{~m}$ by $85 \mathrm{~m}$ region (eight points omitted due to obstruction by supporting columns). The grid was centered to the north and south boundaries of the plaza ceiling and the east/west positioning of the light guide (fig. 1). Vertical illuminance levels in the crosswalk of the roadway were measured at elevations of 60,150 and $210 \mathrm{~cm}$ above the roadway surface. 
All measurements were taken at night to reduce ambient lighting effects. Baseline data was taken, with both the mercury and sulfur lighting systems off, to account for stray light from street lighting and interior building lighting.

Energy consumption for each lighting system was determined by data provided by Fusion Lighting and the Forrestal facility staff.

\section{Results}

The existing mercury HID lighting system for the Forrestal plaza contains 280 recessed fixtures with $175 \mathrm{~W}$ lamps. Due to the age of the system and the lack of maintenance, only 239 of these lamps were operating during the measurement period. The system, as measured, produced 92961 lumens on a floor plane of $2,760 \mathrm{~m}^{2}$, or an average of 33.7 lux over the floor plane (table 1).

Table 1. Forrestal illuminance

\begin{tabular}{|l|c|c|c|c|}
\hline & $\begin{array}{c}\text { Total Lumens } \\
\text { on Work } \\
\text { Plane }\end{array}$ & $\begin{array}{c}\text { Work Plane Area } \\
\text { (square meters) }\end{array}$ & $\begin{array}{c}\text { Coefficient of Utilization } \\
\text { (workplane lumens/ } \\
\text { total lamp lumen output) }\end{array}$ & $\begin{array}{c}\text { Average } \\
\text { Illuminance } \\
\text { (lux) }\end{array}$ \\
\hline $\begin{array}{l}\text { Mercury } \\
\text { System }\end{array}$ & 92,961 & 2,760 & 0.09 & 44 \\
\hline $\begin{array}{l}\text { Sulfur Lamp } \\
\text { System }\end{array}$ & 378,000 & 2,760 & 0.42 & 137 \\
\hline
\end{tabular}

The sulfur lamp/light guide system produced 378,000 lumens over the same area resulting in an average of 137.0 lux over the floor plane. This system produced the greatest horizontal illuminance directly below the light guide with decreasing illuminance towards the outer edges of the plaza. As designed, the sulfur lamp/light guide system produced lower levels of illuminance over the non-walkway areas of the roadway to protect motorists from high angle glare (see fig. 2).

Vertical illuminance measurements taken in the pedestrian walkway revealed a three-fold increase in illuminance at all three elevations when comparing the sulfur lamp system to the mercury lamp system.

The total electrical energy consumed by the existing mercury system was determined by multiplying the number of operating lamps by the total lamp system power, including ballast power. With 239 lamps in operation, the existing mercury lighting system required $48,995 \mathrm{~W}$ of electrical power. The two sulfur lamps combined use $11,800 \mathrm{~W}$ (table 2).

Table 2. Forrestal lamps and power schedule

\begin{tabular}{|l|c|c|c|c|}
\hline & \# of lamps & $\begin{array}{c}\text { Lamp Power } \\
\text { (watts/lamp) }\end{array}$ & $\begin{array}{c}\text { Ballast Power } \\
\text { (watts/lamp) }\end{array}$ & $\begin{array}{c}\text { Total Power } \\
\text { (watts) }\end{array}$ \\
\hline Merc. existing & 239 & 175 & 30 & 48,995 \\
\hline Sulfur & 2 & 5,900 & $0^{*}$ & 11,800 \\
\hline
\end{tabular}

* Magnetron losses are included in lamp power. 
Figure 2. Forrestal plaza floor illuminance graphs
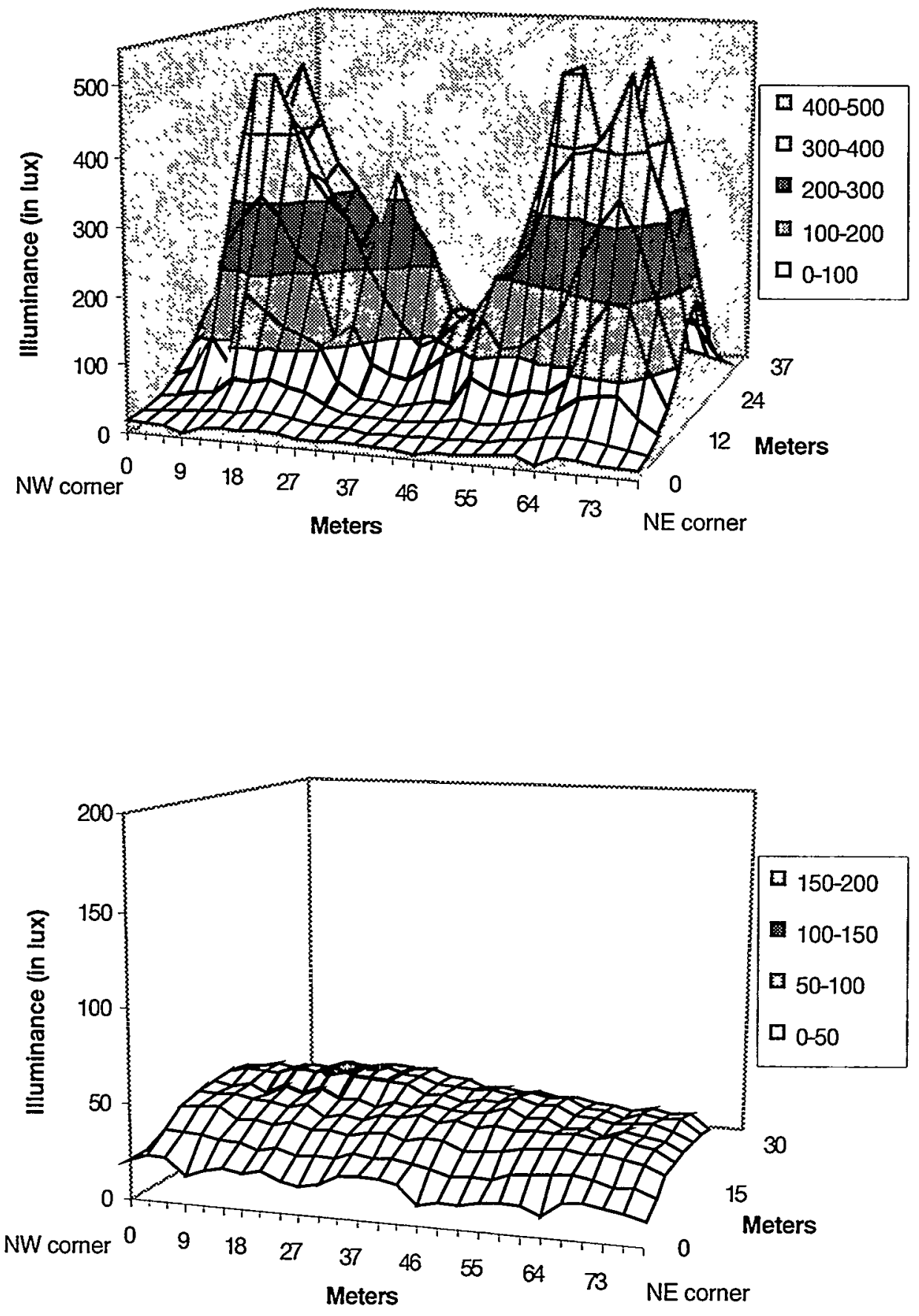

2.b Mercury system 


\section{NASM SITE}

The National Air and Space Museum, which is part of the national Smithsonian Museum complex, chronicles the history and projected future of aeronautics and space exploration. Gallery 114 of NASM houses several of the most significant rockets and crafts of the U.S. space program. The floor space of the gallery is approximately $1,150 \mathrm{~m}^{2}$ in roughly square dimensions, and is densely covered with display items (fig. 3). To accommodate the many tall and ceiling suspended displays, the gallery has a $20 \mathrm{~m}$ high ceiling, and a $19 \mathrm{~m}^{2}$ recessed region for the large missiles. Three sides of the room are primarily walled and the fourth side of the gallery is entirely covered with glass panels allowing for an abundance of daylighting. The new lighting installation, as with the previous one, was designed as a supplement to daylight on cloudy days and during the early evening portion of normal exhibit hours. The Gallery 114 lighting system is also needed for lighting the gallery during post exhibit hours cleaning and frequent night time functions.

Figure 3. Gallery 114 of NASM

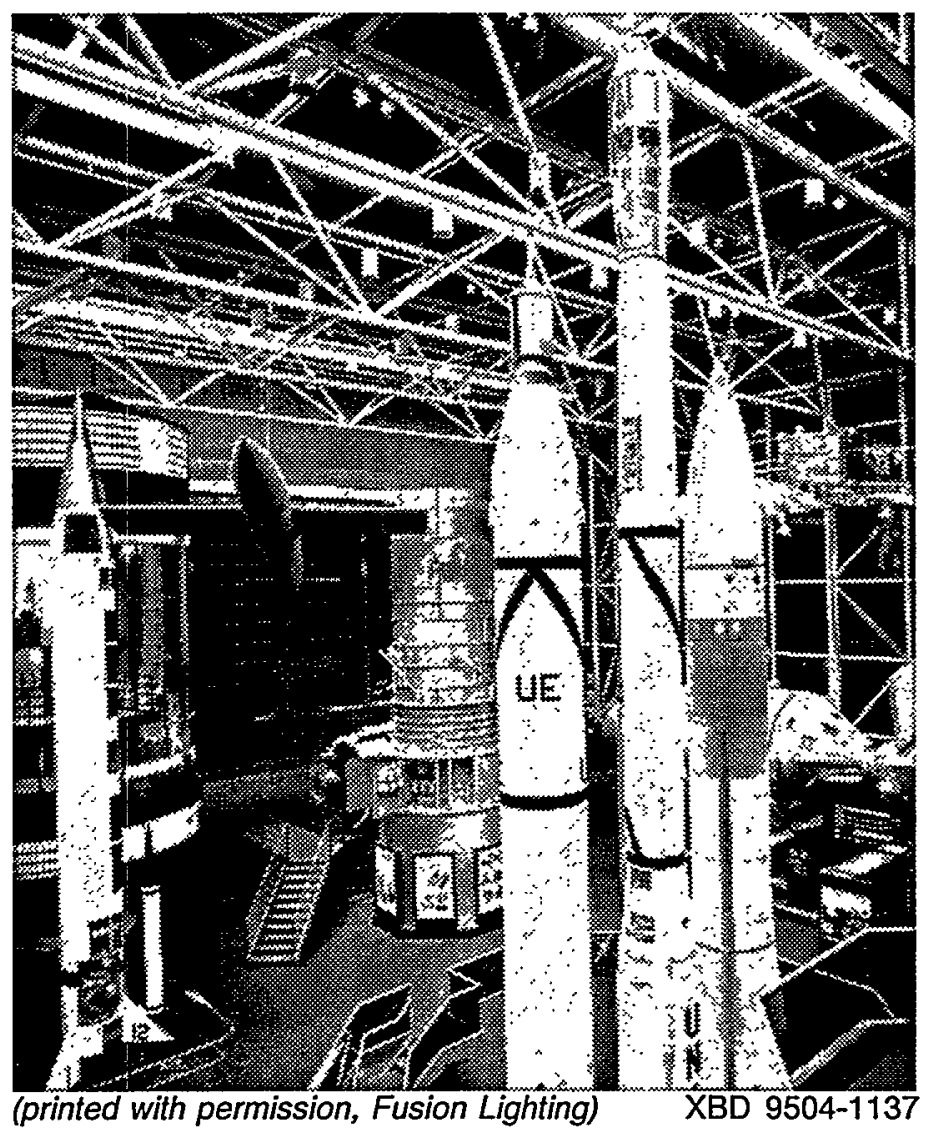

The original lighting system at the NASM gallery employs a series of mercury vapor lights of varying lamp wattages as the primary source of illumination (table 3 ). The majority of the mercury fixtures, as well as several $500 \mathrm{~W}$ incandescent lamps, are evenly distributed over ten horizontal tracks suspended $2,5 \mathrm{~m}$ from the ceiling. 
Table 3. NASM Lamps and power schedule

Original System

\begin{tabular}{|l|c|c|c|c|c|}
\hline Lamp Type & $\begin{array}{c}\text { Lamp } \\
\text { Watts }\end{array}$ & $\begin{array}{c}\text { Ballast } \\
\text { Watts }\end{array}$ & $\begin{array}{c}\text { Total } \\
\text { Lamps }\end{array}$ & $\begin{array}{c}\text { Operational } \\
\text { Lamps }\end{array}$ & $\begin{array}{c}\text { Total Watts } \\
\text { (operational lamps) }\end{array}$ \\
\hline Q500T3W (inc.) & 500 & 0 & 10 & 8 & 4,000 \\
\hline 400W (merc.) & 400 & 54 & 15 & 11 & 4,994 \\
\hline 250W (merc.) & 250 & 35 & 19 & 14 & 3,990 \\
\hline 175W (merc.) & 175 & 25 & 30 & 23 & 4,600 \\
\hline 400W (merc.) & 400 & 54 & 20 & 12 & 5,448 \\
\hline
\end{tabular}

Sulfur System

\begin{tabular}{|l|l|l|l|l|l|}
\hline sulfur lamp & 5,900 & 0 & 3 & 3 & 17,700 \\
\hline
\end{tabular}

As with the Forrestal site, the new lighting system installed at the NASM space gallery combines hollow light guide technology with the new, high efficiency, electrodeless sulfur lamp. Three sulfur lamp luminaires are used to pump light into three $27.4 \mathrm{~m}$ long cylindrical light guides lined with highly reflective prismatic film. The three light guides run north to south, paralleling the ceiling tracks of the original system. A 310,000 lumen sulfur lamp luminaire is optically coupled to the south end of each of the light guides where a second story balcony allows for ease of access and maintenance.

\section{Methods}

The primary field measurements taken at the site comprise a grid of illuminance readings covering the open (non-display) areas of the main floor. The illuminance of the floor plane, as with all other measurements, was taken for both the original and sulfur lamp system.

There are numerous placards and kiosks in the gallery that provide information about the displays. As the visibility of their text and graphics is of great importance, illuminance of the placards and kiosks was measured.

In order to assess and compare the ability of the two systems to adequately illuminate the displays of the gallery, illuminance and luminance measurements were taken with respect to the lighting of several of the feature attractions. Vertical illuminance was measured on the ApolloSoyuz link up, a display which represents the first space docking of American and Soviet crafts. Vertical illuminance and luminance measurements were taken of the Jupiter and Viking rockets whose vertical expanses nearly reach the ceiling.

All photometric measurements were taken at night to eliminate the significant daylighting provided by the north window wall. Illumination measurements were taken with $\mathrm{J} 16$ and $\mathrm{J} 17$ Tektronix photometers in conjunction with their respective illuminance sensors. Luminance measurement were taken with Minolta LS100 and LS110 luminance meters. Energy consumption data for both systems were provided by the NASM lighting designer. 


\section{Results}

Horizontal illuminance measurements were taken over the main open (non-display) areas of Gallery 114 of the National Air and Space Museum. This represents an area of $477 \mathrm{~m}^{2}$. The average illuminance provided by the original system is 48.5 lux. The sulfur lamp system provided an average of 148 lux, representing a three fold increase in average floor illuminance (fig. 2).

The illuminance readings for the numerous placards and kiosks compliment the horizontal floor illuminance in characterizing the over all effectiveness of the lighting system as they are spread all about the room in a wide variety of orientations and are at both 45 degree and vertical inclinations. New system illuminance was an average of 4.2 times greater for the tilted placards and was no less than 1.7 times greater for any particular placard. Vertical placard illuminance increased by an average of 4.3 times under the new system and was never less than twice for any individual measurement.

Vertical Illuminance measurements were taken to characterize the amount of light reaching two of the prominent displays in the gallery; the Viking rocket and the Apollo-Soyuz link-up. The Viking rocket is a vertical display (extending from approximately $12 \mathrm{~m}$ above ground level) and the Apollo-Soyuz a horizontal structure (extending across over $21 \mathrm{~m}$ of floor space at an average center height of about $4.5 \mathrm{~m}$ ). The vertical illuminance serving to illuminate these displays increased by an average of 2.4 times for the Viking rocket and 4,4 times for the Apollo-Soyuz under the new system.

Table 4. Smithsonian photometric summary

\begin{tabular}{|l|c|c|c|}
\hline \multicolumn{1}{|c|}{$\begin{array}{c}\text { Measurement } \\
\text { Location }\end{array}$} & $\begin{array}{c}\text { Mercury System Average } \\
\text { Illuminance }\end{array}$ & $\begin{array}{c}\text { Sulfur System } \\
\text { Average } \\
\text { Illuminance }\end{array}$ & $\begin{array}{c}\text { Average } \\
\text { Percent } \\
\text { Increase }\end{array}$ \\
\hline Open Floor & $48.5 \mathrm{lux}$ & $148.0 \mathrm{lux}$ & 205 \\
\hline Tilted Placard & $47.3 \mathrm{lux}$ & $197.1 \mathrm{lux}$ & 317 \\
\hline Vertical Placard & $13.5 \mathrm{lux}$ & $57.7 \mathrm{lux}$ & 327 \\
\hline Apollo-Soyuz Vertical & $24.6 \mathrm{lux}$ & $108.4 \mathrm{lux}$ & 341 \\
\hline Viking Rocket Vertical & $25.5 \mathrm{lux}$ & $62.1 \mathrm{lux}$ & 144 \\
\hline Jupiter Rocket (luminance) & $5.5 \mathrm{~cd} / \mathrm{m}^{2}$ & $2.1 \mathrm{~cd} / \mathrm{m}^{2}$ & 665 \\
\hline
\end{tabular}

Several luminance measurements were taken along the Jupiter rocket, which extends nearly to the ceiling. These measurements relate to the brightness of this central display as seen from a popular visitor viewing spot. The luminance of the Jupiter rocket increased an average of 7.7 times when switching from the old to new system. In particular, the new light guide system did a much better job of illuminating the upper portions of the rocket when compared to the previous lighting system.

The total energy consumption of the original lighting system is $23 \mathrm{~kW}$, with the current number of operational lamps. The three sulfur lamps use $5900 \mathrm{~W}$ each requiring a total of $17.7 \mathrm{~kW}$ of power to run the new lighting system.

\section{DISCUSSION}

Several factors contribute to the dramatic differences in lighting levels and energy consumption between the new and old lighting systems at both of the installation sites. Primarily, the decayed condition of the existing mercury systems resulted in illuminance levels far below those that would be achieved by new, properly designed HID lighting systems. A companion paper elaborates on comparisons of the sulfur lamp/light guide to hypothetical HID lighting systems 
(Crawford et al. 1995). However, the efficiency of light distribution and ease of maintenance for the sulfur lamp/light guide system make this new technology an attractive alternative for a variety of lighting applications (Aizenberg et al. 1988).

In the Forrestal installation the $175 \mathrm{~W}$ mercury HID lamps were placed in fixtures designed for PAR reflector style lamps. The overall fixture efficiency, with a non-reflector HID lamp, is estimated to be on the order of $30 \%$. The mercury lamps in place have not been replaced for several years, thus their lumen depreciation is calculated at 0,6 . The fixtures are in an outdoor environment, above a roadway and are therefore subjected to a high level of dirt accumulation. Fixture dirt depreciation is approximated at 0,6. The geometry of the ceiling coffer also compounds the inefficiency of the existing mercury system. The concrete walls of the coffers absorb a large portion of the light directed on them. With the inappropriate lamp fixture combination, only $63 \%$ of the flux leaving the fixture reaches the plaza floor. All of these factors combined result in an extremely low system efficiency. Replacing the existing mercury HID system with a new HID system would result in increased efficiency, however there are maintenance issues that still favor the installation of a sulfur lamp/light guide system.

The height of the Forrestal plaza ceiling and the plaza floor construction compound the problems of the HID lighting system. The floor consists of concrete pavers placed on top of a waterproof membrane, which protects the subterranean portion of the building. The mercury fixtures are roughly $10.7 \mathrm{~m}$ above the plaza floor, thus requiring heavy equipment for lamp replacement and fixture maintenance. The fragility of the plaza floor's membrane places a restriction on its loading. Therefore, lamp replacement and fixture maintenance is a non-trivial exercise. Consequently there has been no known lamp replacement or fixture maintenance within the past eight to ten years. Of the 280 mercury HID lamps contained within the measurement area, 41 lamps had reached the end of their lives and the remaining 239 exhibited extremely low lumen output.

The sulfur lamp/light guide system consists of two lamps and a single, closed system light guide. System maintenance is therefore reduced to periodic, exterior wiping of a single surface and maintenance on two light sources, while the HID type system requires maintenance on 280 individual lamps and fixtures. Cleaning requirements for the light guide have not been determined, yet they will undoubtedly be significantly less than for a 280 lamp system.

Similar factors contributed to the inefficiency of the previous NASM system, and hence the well suited application for a sulfur lamps/light guide system. Several of the lamps in the original system were burned out at the time that field measurements were taken (table 3). This lack of maintenance was due in part to the knowledge that a new system was to be installed, but as well represents the primary reason for the choice of the new system; maintenance of the original lighting is expensive, labor intensive and often impractical. To relamp or clean the existing fixtures requires the use of large automated lift equipment that must maneuver around the high density of displays both at floor level and throughout the space of the gallery. Operating the lift equipment is time consuming and requires skilled labor. With over 80 fixtures mounted to the 18 $\mathrm{m}$ high ceiling tracks, it is not cost effective to relamp fixtures as they burn out. Due to the particular difficulty of reaching certain fixtures, some have never been relamped. Additionally, the original system at NASM utilized several high wattage incandescent lamps which are inherently inefficient.

With the new system, not only has the total number of lamps been greatly reduced and lamp life increased, but due to the unique design opportunities available with light guides the sulfur lamps are located above a second story balcony which dramatically improves ease of access and maintenance. As with the Forrestal site, the sulfur lamp/light guide system at NASM has successfully achieved the goal of increased illumination while simultaneously decreasing the significant energy and maintenance costs associated with properly illuminating large high ceiling spaces. 


\section{ACKNOWLEDGMENT}

This work was supported by the Assistant Secretary for Energy Efficiency and Renewable Energy, Office of Building Technologies, Building Equipment Division of the U.S. Department of Energy under Contract No. DE-AC03-76SF00098.

\section{REFERENCES}

Aizenburg, J., Pyatigorsky, V., Buchman, G. 1988. "Slit Light Guides." Science in the USSR, ISSN 0203-4638:34-40.

Crawford, D., Gould, C., Packer, M., Rubinstein, F., Siminovitch, M. 1995. "Photometric and Energy Assessment of a Novel Light Guide System." To be presented at the IESNA Annual Conference, August 1995.

Audin, L. 1995 "Lighting a New Age with Microwave." Architectual Record Lighting: 12-13.

Dolan, T.D., Ury M G., Wood C.H. 1992. "A Novel High Efficiency Microwave Powered Light Source." 6th International Symposium on the Science and Technology of Light Sources, September, 1992.

Gilmore, V.E. 1988. "Piping Light." Popular Science: 77-79,117.

MacLennan, D.A., Dolan J T., Turner B.P. 1993. "Small Long-Lived Source for Projection-Display Applications." SID (Society for Information Display) Digest.

Saxe, S. 1989. "Prismatic Film Light Guides: Performance and Recent Developments." Solar Energy Materials: 95-109.

Scott, J.E., Whitehead, L.A. "Distribution of Light with Prism Light Guides." Proceedings of Illuminating Engineering Society Conference, August 1984.

"3M Scotch Optical Lighting Film: General Theory." 1988. 3M Application Bulletin. 